\title{
Different patterns of glaucoma management in South Punjab.
}

1. MCPS, FCPS,

FRCS, Fellowship in Vitreo-Retina Professor \& Head Ophthalmology Nishtar Medical University, Multan.

2. MBBS

Resident Medical Officer

Ophthalmology

Nishtar Medical University, Multan.

3. MBBS, FCPS

Senior Registrar Ophthalmology Nishtar Medical University, Multan

4. $4^{\text {th }}$ Year MBBS Medical Student Nishtar Medical University, Multan.

5. $4^{\text {th }}$ Year MBBS Medical Student

Nishtar Medical University, Multan

6. $4^{\text {th }}$ Year MBBS Medical Student

Nishtar Medical University, Multan.

Correspondence Address:

Dr. Rashad Qamar Rao

17- Nishtar Estate,

Nishtar Medical University, Multan.

drrashadqr@yahoo.com

Article received on:

02/03/2020

Accepted for publication:

$11 / 07 / 2020$
Rashad Qamar Rao', Wamiq Mehmood ${ }^{2}$, Raza $\mathrm{Ali}^{3}$, Akifa Abbas $^{4}$, Waseem Sajjad ${ }^{5}$, Afifa Batool

ABSTRACT... Objectives: Glaucoma is the most common blinding condition in South Punjab of Pakistan and its management is a challenge due to illiteracy and lack of financial resources. Study Design: Randomized Clinical Trial. Setting: Department of Ophthalmology Nishtar Hospital Multan. Period: June 2016 - June 2018. Material \& Methods: We have randomly selected patients on the basis of Cup to Disc ratio and applied randomized clinical trial of both medical and surgical modalities of glaucoma management to observe the visual outcomes in terms of Intraocular pressure and Cup to disc ratio. Results: The vision survival of trabeculectomy in pseudophakics was $88.77 \%$ while only $9.8 \%$ was the survival rate of trabeculectomy in phakics. $90 \%$ of 31 phakic patients who underwent trabeculectomy failed. Similarly patients on 3 IOP lowering drugs had $70 \%$ vision survival rate out of 260 patients treated. Patients with C-D ratio 0.8 had maximum failure rate of $69 \%$ out of 78 patients in which medical treatment failed. Conclusion: Trabeculectomy significantly reduced the intraocular pressure in patients in which pharmacological treatment failed.The success rate of trabeculectomy among pseudophakics is high. In Phakics, when only Trabeculectomy is done, success rate is low. When trabeculectomy and clear lens extraction is done simultaneously, the success rate is slightly higher. When trabeculectomy is done after clear lens extraction, the success rate is highest. In case of Cataract, cataract extraction and trabeculectomy when done simultaneously, show low success rate. When trabeculectomy was done after cataract extraction, shows highest success rate.

Key words: $\quad$ Glaucoma, Management, South Punjab, Trabeculectomy.

Article Citation: Rao RQ, Mehmood W, Ali R, Abbas A, Sajjad W, Batool A. Different patterns of glaucoma management in South Punjab. Professional Med J 2020; 27(12):2586-2590. https://doi.org/10.29309/TPMJ/2020.27.12.4605

\section{INTRODUCTION}

Glaucoma by definition is basically a chronic and progressive optic neuropathy which is caused by a group of ocular conditions which leads to the damage of optic nerve with loss of visual functions. ${ }^{1,2}$ The most common known risk factor is increased IOP (normal is $12-22 \mathrm{mmHg}$ ). The modern goals of glaucoma management are to prevent glaucomatous optic nerve damage, preserve visual field defects of the patient and finally the total quality of life with minimal side effects of medications or the surgical procedures. ${ }^{3-5}$

Glaucoma is a $4^{\text {th }}$ leading cause of blindness according to a survey done in Pakistan in 2007. Which showed that glaucoma if not managed properly can easily lead to the top blinding conditions in Pakistan. ${ }^{6}$ As awareness of glaucoma, its complications and treatment is still an issue in the region due to illiteracy, lack of financial resources and motivation among patients. ${ }^{7}$ All these factors are the reason of glaucoma being a Silent killer of vision in our society which makes glaucoma management more challenging and crucial for saving vision. ${ }^{8}$

\section{MATERIAL \& METHODS}

We screened 500 patients irrespective of gender and age over 2 years (from June 2016 - June 2018) period for their Cup to Disc ratio. Then we randomly assigned medical and surgical treatment modalities to patients and followed the outcomes. We linked the results with lenticular status of the patient i.e. phakic or pseudophakic. We also recorded the results of patients who underwent trabeculectomy as well as cataract surgery in a single sitting. 


\section{Inclusion Criteria}

1. Cup to disc ratio 0.7-0.9.

\section{Exclusion Criteria}

Includes

1. C-D ratio less than 0.7

2. Already undergone surgery for IOP control.

3. Lost to follow up

"Success or Survival" means the recovery of visual acuity and "Failure" means the deterioration of vision to non perception of light, inability to decrease $\mathrm{C}-\mathrm{D}$ ratio and attain target IOP.

Target IOP was $<12 \mathrm{mmHg}$

We also recorded if the subjects had prior knowledge about their ailment, if they had previous medical record which included their previous investigations, treatments and further plans. Patients were followed according to their CD ratio, target IOP and lenticular status (i.e. phakic or pseudophakic). To remove the Observer bias, we restricted the surgeon number to one.We used Microsoft excel for data analysis. Following is graphical and tabular presentation of observed outcomes.

Moving on, only 410 patient had proper follow up for the study, of which 150 were managed by surgery and 260 were managed by pharmacotherapy

Based on patients with proper follow up, we planned following procedures and observed the outcome

\section{RESULTS}

\section{Surgical Management Outcomes}

\begin{tabular}{|c|c|c|}
\hline Cupping & Patients & Percentage \\
\hline 0.70 & 215 & $43 \%$ \\
\hline 0.80 & 107 & $21 \%$ \\
\hline 0.90 & 178 & $35 \%$ \\
\hline
\end{tabular}

Table-I. Patients with glaucoma by cup to disc ratio $\mathrm{n}=\mathbf{5 0 0}$

\begin{tabular}{|l|c|c|}
\hline \multicolumn{1}{|c|}{ Investigation } & Patients & Percentage \\
\hline IOP record & 330 & $65.47 \%$ \\
\hline Visual Field & 88 & $17.46 \%$ \\
\hline OCT & 43 & $8.53 \%$ \\
\hline CCT & 43 & $8.53 \%$ \\
\hline
\end{tabular}

Table-II. Patients having previous investigation records.

\begin{tabular}{|l|c|}
\hline \multicolumn{1}{|c|}{ Glaucoma Cases } & No of Patients \\
\hline Known cases & 291 \\
\hline Recently diagnosed & 209 \\
\hline
\end{tabular}

Table-III. Known status of glaucoma patients

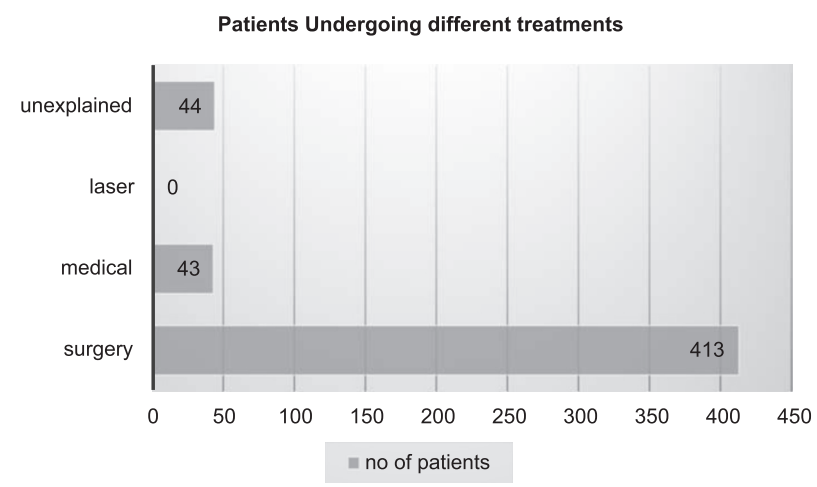

Figure-1. Patients having different plans of treatment previously.

\begin{tabular}{|l|c|c|}
\multicolumn{1}{|c|}{ Treatment } & $\begin{array}{c}\text { Number of } \\
\text { Patients }\end{array}$ & $\begin{array}{c}\text { Per- } \\
\text { centage }\end{array}$ \\
\hline Surgicallyby Trabeculectomy & 150 & $36.58 \%$ \\
\hline Pharmacologically & 260 & $63.41 \%$ \\
\hline Total & 410 & $100 \%$ \\
\hline
\end{tabular}

Table-IV. Number of patients undergoing two management plans $n=360$

\begin{tabular}{|l|c|c|}
\hline $\begin{array}{c}\text { Cup to Disk } \\
\text { Ratio }\end{array}$ & $\begin{array}{c}\text { Number of } \\
\text { Patients }\end{array}$ & Percentage \\
\hline 0.9 & 82 & $54.66 \%$ \\
\hline 0.8 & 37 & $24.66 \%$ \\
\hline 0.7 & 31 & $20.66 \%$ \\
\hline Total & 150 & $100 \%$ \\
\hline
\end{tabular}

Table-V. Number of patients with certain cup to disk ratio undergoing Trabeculectomy $n=150$

We categorised 150 trabculectomy patients into three groups

- Group 1:Pseudophakics ( $\mathrm{N}=52)$, (who already have undergone cataract surgery before taking part in our study) had trabeculectomy 
with success* of $88.77 \%$.

- Group 2: Phakics $(\mathrm{N}=59)$, out of these patients 31 undergone only trabeculectomy with success of only $9.86 \%$. 22 undergone combined clear lens extraction and trabeculectomy with success of $50 \%$. 6 patients underwent clear lens extraction first and then trabeculectomy later with success of 83.33\%.

- Group 3: Cataractus ( $\mathrm{N}=39$ ), out of these 12 undergone combined cataract extraction and trabeculectomy with success of $25 \% .27$ undergone first cataract extraction and later trabeculectomy with success of $70.37 \%$.

\section{Medical Management Outcomes}

Patients on drugs were divided based upon the number of drugs they were advised. Their overall outcomes were recoded.

\section{DISCUSSION}

This study is somewhat similar to the study of Wishartand Atkinson, who recommended cataract extraction surgery as the first procedure in eyes of the patient with cataract and primary angle closure glaucoma, rather than combined cataract and filtering surgery together. ${ }^{9}$ The study of James $\mathrm{C}$ and Bobrow also supports our study. It shows that after an average of $\mathbf{8 7}$ months of follow-up of cataract extraction and IOL implantation reduced IOP by $4.4 \mathrm{mmHg}$. After almost 80 months of follow-up of cataract extraction surgery, IOL implantation, and trabeculectomy reduced IOP by $8.2 \mathrm{mmHg}$. But they also used medications for the treatment along with surgery. ${ }^{10}$ Study of Salmon shows that those Phakic patients who had undergone just trabeculectomy without earlier removal of lens, one third of the patients required a second surgical procedure (either a second trabeculectomy or a cataract extraction) within 3 years of. ${ }^{11}$ Some studies suggest only Lens extraction to be effective in lowering intraocular pressure in PACG and has even been advocated as an alternative to filtration surgery in select cases as a result. ${ }^{12-14}$ Doing glaucoma surgical procedure alone may accelerate the cataract formation, which means the patient would be in need of cataract surgery soon in future. Performing cataract extraction surgery alone may decrease the intraocular pressure (IOP) independently ${ }^{15,16}$,

\begin{tabular}{|l|l|c|c|c|}
\hline \multicolumn{1}{|c|}{$\begin{array}{c}\text { Lenticular } \\
\text { Condition }\end{array}$} & \multicolumn{1}{c|}{ Procedure } & Survived & Failed & Total \\
\hline Pseudophakics & Trabeculectomy & $42(88.77 \%)$ & $10(19.23 \%)$ & 52 \\
\hline \multirow{3}{*}{ Phakics } & Only Trabeculectomy & $3(9.86 \%)$ & $28(90.32 \%)$ & 31 \\
\cline { 2 - 5 } & Simultaneous Clear Lens Extraction \& Trabeculectomy & $11(50 \%)$ & $11(50 \%)$ & 22 \\
\cline { 2 - 5 } & Clear Lens Extraction \& Later Trabeculectomy & $5(83.33 \%)$ & $1(16.67 \%)$ & 6 \\
\hline \multirow{2}{*}{ Cataract } & Simultaneous Cataract Extraction \& Trabeculectomy & $3(25 \%)$ & $9(75 \%)$ & 12 \\
\cline { 2 - 5 } & Cataract Extraction \& Later Trabeculectomy & $19(70.37 \%)$ & $8(29.63 \%)$ & 27 \\
\hline Total & & $83(55.33 \%)$ & $67(44.67 \%)$ & 150 \\
\hline
\end{tabular}

Table-VI. Outcome of different procedures done under different lenticular conditions $n=150$

\begin{tabular}{|c|c|c|c|c|}
\hline Number of Drug(s) & Number of Patients & Total Survived & Total Failed & Total \\
\hline 1 & $31(18.46 \%)$ & \multirow{3}{*}{$182(70 \%)$} & \multirow{3}{*}{78 (30\%) } & \multirow{3}{*}{260 (100\%) } \\
\hline 2 & 55 (27.69\%) & & & \\
\hline 3 & 124 (54.23\%) & & & \\
\hline
\end{tabular}

\begin{tabular}{|c|c|c|}
\hline Cup to Disk Ratio & Number of Patients & Percentage \\
\hline 0.7 & 7 & $9.52 \%$ \\
\hline 0.8 & 55 & $69.84 \%$ \\
\hline 0.9 & 16 & $20.63 \%$ \\
\hline
\end{tabular}

Table-VIII. Number of patients with respect to their cup to disk ratio in which pharmacological treatment failed $\mathrm{n}=78$ 
but this is variable, especially in poorly controlled glaucoma with severe visual field defects. ${ }^{13}$ There is inconclusive research evidence of an increased risk of complications while doing combined surgery over cataract surgery alone, and the information about long-term outcomes (follow-up of five years or more) is unavailable. ${ }^{17,18}$

In study of glaucoma cases, the diagnosed cases are less than the known cases

Cup to disc ratio, IOP record, visual field and other parameters should be studied for treatment and control of glaucoma

Different medical and surgical procedures should be studied.

The prognosis of surgical procedures are discussed whereas the Pharmalogical treatments are not studied with the different survival rate

Glaucoma should bestudied with other endocrinal systemic and local disorder in correlation with ocular congenital and acquired disorders

Congenital and acquired Glaucoma should be studied separately with different parameters and treatments

\section{CONCLUSION}

Trabeculectomy significantly reduced the intraocular pressure in patients in which pharmacological treatment failed.

The success rate of trabeculectomy among pseudophakics is high.

In Phakics, when only Trabeculectomy is done, success rate is low. When trabeculectomy and clear lens extraction is done simultaneously, the success rate is slightly higher. When trabeculectomy is done after clear lens extraction, the success rate is highest.

In case of Cataract, cataract extraction and trabeculectomy when done simultaneously, show low success rate. When trabeculectomy was done after cataract extraction, shows highest success rate.

The success rate of only trabeculectomy is higher among pseudophakics as compared phakics.

The success rate of trabeculectomy done after lens extraction shows higher success rate in phakics as compared to cataract patients.

Trabeculectomy should be done after the removal of cataract to achieve higher success rates.

Those patients with cup to disk ratio of 0.8 show highest rate of pharmacological treatment failure. Copyright@ 11 July, 2020.

\section{REFERENCES}

1. Mantravadi AV, Vadhar N. Glaucoma. Primary care. 2015; 42(3):437-49.

2. Michelessi $M$, Lucenteforte $E$, Oddone $F$, Brazzelli M, Parravano M, Franchi S, et al. Optic nerve head and fibre layer imaging for diagnosing glaucoma. The Cochrane database of systematic reviews. 2015 (11):Cd008803

3. Thomas R, Loibl K, Parikh R. Evaluation of a glaucoma patient. Indian Journal of Ophthalmology. 2011; 59(7):43-52.

4. Noecker RJ. The management of glaucoma and intraocular hypertension: Current approaches and recent advances. Therapeutics and clinical risk management. 2006; 2(2):193-206.

5. Parikh R, Parikh S, Navin S, Arun E, Thomas R. Practical approach to medical management of glaucoma. Indian Journal of Ophthalmology. 2008; 56(3):223-30.

6. Dineen B, Bourne R, Jadoon Z, Shah SP, Khan MA, Foster $A$, et al. Causes of blindness and visual impairment in Pakistan. The Pakistan national blindness and visual impairment survey. British journal of ophthalmology. 2007; $91(8): 1005-10$.

7. Butt $\mathrm{NH}$, Ayub $\mathrm{MH}$, Ali $\mathrm{MH}$. Challenges in the management of glaucoma in developing countries. Taiwan journal of ophthalmology. 2016; 6(3):119-22.

8. Farooq S, Jaffar S, Kausar A. Determinants of glaucoma awareness in urban punjab. Pakistan Armed Forces Medical Journal. 2015; 65(5):591-4. 
9. Wishart PK, Atkinson PL. Extracapsular cataract extraction and posterior chamber lens implantation in patients with primary chronic angle-closure glaucoma: Effect on intraocular pressure control. Eye (London, England). 1989; 3 ( Pt 6):706-12.

10. Bobrow JC. Cataract extraction and lens implantation with and without trabeculectomy: An intrapatient comparison. Transactions of the American Ophthalmological Society. 1998; 96:521-56.

11. Salmon JF. The role of trabeculectomy in the treatment of advanced chronic angle-closure glaucoma. Journal of glaucoma. 1993; 2(4):285-90.

12. Sommer A, Tielsch JM, Katz J, Quigley HA, Gottsch JD, Javitt J, et al. Relationship between intraocular pressure and primary open angle glaucoma among white and black Americans. The Baltimore Eye Survey. Archives of ophthalmology (Chicago, III : 1960). 1991; 109(8):1090-5.

13. Bojikian KD, Chen PP. Intraocular pressure after phacoemulsification in open-angle glaucoma patients with uncontrolled or marginally controlled glaucoma and/or with severe visual field loss. Journal of glaucoma. 2018; 27(2):108-14.
14. Gunning FP, Greve EL. Lens extraction for uncontrolled angle-closure glaucoma: Long-term follow-up. Journal of cataract and refractive surgery. 1998; 24(10):1347-56.

15. Hayashi K, Hayashi H, Nakao F, Hayashi F. Effect of cataract surgery on intraocular pressure control in glaucoma patients. Journal of cataract and refractive surgery. $2001 ; 27(11): 1779-86$.

16. Tham CC, Kwong YY, Baig N, Leung DY, Li FC, Lam DS. Phacoemulsification versus trabeculectomy in medically uncontrolled chronic angle-closure glaucoma without cataract. Ophthalmology. 2013; 120(1):62-7.

17. Zhang ML, Hirunyachote $P$, Jampel H. Combined surgery versus cataract surgery alone for eyes with cataract and glaucoma. The Cochrane database of systematic reviews. 2015 (7):Cd008671.

18. Masis M, Mineault PJ, Phan E, Lin SC. The role of phacoemulsification in glaucoma therapy: A systematic review and meta-analysis. Survey of ophthalmology. 2018; 63(5):700-10.

\begin{tabular}{|c|c|c|c|}
\hline \multicolumn{4}{|c|}{ AUTHORSHIP AND CONTRIBUTION DECLARATION } \\
\hline Sr. \# & Author(s) Full Name & Contribution to the paper & Author(s) Signature \\
\hline 1 & Rashad Qamar Rao & $\begin{array}{l}\text { Main investigator and operating } \\
\text { surgeon, Study design setting } \\
\text { and final data review and work } \\
\text { approval. }\end{array}$ & \\
\hline 2 & Wamiq Mehmood & $\begin{array}{l}\text { Author contributed in data } \\
\text { analysis and collection. }\end{array}$ & Rathr \\
\hline 3 & Raza Ali & $\begin{array}{l}\text { Author contributed in data } \\
\text { analysis and collection. }\end{array}$ & arife \\
\hline 4 & Akifa Abbas & $\begin{array}{l}\text { Data collection and literature } \\
\text { review. }\end{array}$ & wasem. \\
\hline 5 & Waseem Sajjad & $\begin{array}{l}\text { Data collection and literature } \\
\text { review. }\end{array}$ & \\
\hline 6 & Afifa Batool & $\begin{array}{l}\text { Data collection and literature } \\
\text { review. }\end{array}$ & \\
\hline
\end{tabular}

